\title{
PRODUÇÃO DE MUDAS DE SAPOTIZEIRO POR MEIO DA ESTAQUIA EM DIFERENTES SUSBTRATOS
}

\author{
SUGUINO, Eduardo ${ }^{1 *}$ \\ MARTINS, Adriana Novais ${ }^{2}$ \\ HEIFFIG-DEL AGUILA, Lília Sichmann ${ }^{3}$ \\ AGUILA, Juan Saavedra del ${ }^{4}$ \\ MINAMI, Keigo ${ }^{5}$
}

RESUMO: A produção comercial do sapotizeiro é feita por meio de mudas enxertadas, mas pomares com baixo custo de implantação e alta qualidade de plantas visando o mercado de frutas frescas podem se tornar uma opção para a agricultura familiar. Esta pesquisa teve como objetivo verificar a viabilidade de produção de mudas de sapotizeiro por meio da estaquia em diferentes substratos, sem a utilização de reguladores vegetais. $\mathrm{O}$ experimento foi conduzido em delineamento estatístico inteiramente ao acaso, com 5 repetições, 4 tratamentos (substratos: areia média lavada, fibra de coco, casca de café carbonizada e Plantmax®) e 18 estacas por unidade experimental, totalizando 360 observações, colocadas para enraizar em bandejas de poliestireno expandido de 72 células. A escala de notas foi utilizada para avaliar a qualidade das mudas obtidas. Os dados obtidos foram analisados com auxílio do procedimento CATMOD do programa estatístico SAS (2003). O substrato fibra de coco foi o que possibilitou a formação das raízes de melhor qualidade.

Palavras chave: Achras zapota. Manilkara zapota. Estacas. Propagação vegetativa.

\section{PRODUCTION OF SAPOTI SEEDLINGS THROUGH CUTTINGS IN DIFFERENT SUBSTRATES}

SUMMARY: The commercial production of the sapoti plant is made through grafting, but orchards with low cost and high quality of plants for the fresh fruits market can become an option to family agriculture. This research had as objective verifies the viability to produce sapoti transplants throughout cuttings in different substrates. The experiment was conducted in a completely randomized design, with 5 replications, 4 treatments (substrates: medium washed sand, coconut fiber, charred peel of coffee and Plantmax ${ }^{\circledR}$ ) and 18 cuttings for each experimental unit, totalizing 360 observations, in trays of expanded polystyrene. The score rating were used to evaluate the quality of the obtained seedlings. The data were analyzed according to CATMOD procedure from SAS (2003) statistical program. The best quality of roots was obtained in coconut fiber treatment.

Keywords: Achras zapota. Manilkara zapota. Cuttings. Vegetative propagation.

\footnotetext{
1 APTA Centro Leste, /DDD/SAA, Av. Bandeirantes, 2419, CEP 14030-670, Ribeirão Preto - SP; esuguino@apta.sp.gov.br. Bolsista FAPESP.* autor para correspondência.

2 APTA Centro Oeste/DDD/SAA, Rua Andrade Neves, 81, CEP 17515-400. Marília, SP, Brasil.; adrianamartins@apta.sp.gov.br.

3 Embrapa Clima Temperado - ETB. BR 392, km 78 - Cx. Postal 403, CEP 96010-971, Pelotas -RS. lilia.sichmann@cpact.embrapa.br.

${ }^{4}$ Departamento de Fitotecnia, Seção de Fruticultura - Faculdade de Agronomia Eliseu Maciel - UFPel, Campus Universitário, CP 354, CEP 96010-900. Pelotas - RS. Bolsista FAPESP. juan.delaguila@ufpel.edu.br

5 Departamento de Produção Vegetal, ESALQ/USP, Avenida Pádua Dias, 11, CP 09, CEP 13418-900. Piracicaba - SP; kminami@ esalq.usp.br.
} 


\section{INTRODUÇÃO}

Originário das regiões de clima tropical como México e América Central, o sapoti é encontrado praticamente em todas as regiões tropicais e subtropicais da Ásia, Américas e Oceania (LORENZI et al., 2006).

A Embrapa por meio da unidade Embrapa Agroindústria Tropical (Fortaleza/CE) lançou suas primeiras cultivares de sapoti (BRS 227) e sapota (BRS 228). Denominadas, respectivamente, Sapoti Ipacuru e Sapota Tropical o primeiro com formato ovóide e o segundo, com formato mais arredondado, que recebeu este nome por ser semelhante ao fruto da mesma família conhecido como Pouteria sapota (MORAIS et al., 2006).

Devido aos dados obtidos, em longo prazo, sobre a saúde de pessoas com dieta rica em frutas e vegetais, estes estão tomando o lugar na mesa de refeições, de alimentos considerados menos saudáveis como carnes e doces (RIMM, 2002). Regiões tropicais produzem uma enorme variedade de frutos comestíveis, no entanto, muitos poucos são consumidos em larga escala e isso se deve à baixa disponibilidade de alguns tipos de frutos, falta de conhecimento da produção e também à qualidade do fruto disponível (LETERME, 2006).

Esta frutífera adapta-se bem às condições edafoclimáticas de todo o Brasil, especialmente no norte e nordeste, onde seu fruto, que confere um sabor adocicado e levemente adstringente, é muito apreciado e consumido sob diversas formas, principalmente in natura. (MIRANDA et al., 2002).

O fruto do sapoti pode ser considerado um alimento completo, pois é rico em vitaminas, carboidratos, fibras e proteínas (JANGAM et al., 2008). É geralmente propagado por sementes, mas devido ao processo ser lento e ocorrer tardiamente isso prejudica o estudo do potencial e possibilidades de exploração desta frutífera e a expansão da cultura (AZERÊDO et al., 2002)

Para plantios comerciais de sapoti, a formação de mudas por meio da propagação assexuada é a mais recomendada, e embora mais dispendiosas que a propagação seminal, possibilita a formação de mudas idênticas e em larga escala, que em sua maioria trazem consigo a capacidade de frutificar precocemente (BANDEIRA et al., 2003).

Lederman et al. (2001) relatam que, apesar da dificuldade de obtenção de mudas de sapotizeiro por meio da estaquia, a combinação de fatores como a utilização casas de vegetação com nebulização intermitente e substratos apropriados, tem sido possível o enraizamento de estacas de sapotizeiro.

Quanto mais baixos forem os custos da produção de mudas por estaquia, maiores 
serão as chances desta técnica se tornar usual (RUFATO; KERSTEN, 2000), e o uso de substâncias promotoras de enraizamento na produção de mudas por estaquia de algumas espécies aumenta o preço final da muda obtida e este fator pode ser limitante para a expansão da cultura.

Assim esse trabalho visou avaliar a viabilidade obtenção de mudas de qualidade de sapotizeiro por meio da estaquia em diferentes substratos.

\section{MATERIAL E MÉTODOS}

O experimento foi conduzido nas dependências do Departamento de Produção Vegetal da Escola Superior de Agricultura "Luiz de Queiroz", USP, em Piracicaba, SP, no dia 22 de outubro de 2003, em câmara de nebulização intermitente. Os nebulizadores estavam programados para funcionar durante dez segundos em intervalos de quinze minutos.

O material vegetativo utilizado foi coletado de uma planta matriz adulta de sapotizeiro localizada no município de Piracicaba - SP, no período da manhã. As estacas logo que retiradas dos ramos foram colocadas em um recipiente com água para evitar a perda de umidade. As estacas semilenhosas foram retiradas da porção apical (primeiros $30 \mathrm{~cm}$ ) dos ramos e comprimento em torno de $20 \mathrm{~cm}$.

O delineamento estatístico adotado foi o inteiramente ao acaso, cujos tratamentos consistiam em quatro diferentes substratos (areia lavada, fibra de coco, casca de café carbonizada e Plantmax®) colocados em bandeja de poliestireno expandido de 72 células. Utilizou-se 5 repetições e cada unidade experimental foi composta de 18 estacas perfazendo um total de 360 avaliações.

A utilização da escala de notas é simples, agiliza o processo de avaliação, não é destrutiva e não é dependente de equipamentos como balanças de precisão e estufas de secagem, dentre outros, e isso diminui o custo do processo de obtenção destas mudas e neste caso podem diferenciar em termos qualitativos as raízes obtidas nas estacas de sapotizeiro.

Foi adotada a seguinte escala de notas (Figura 1) para as estacas vivas: nota $1=$ ausência de raízes; nota $2=$ enraizamento ruim; nota 3 = enraizamento regular; nota $4=$ enraizamento bom; nota 5 = enraizamento ótimo. As notas da escala utilizada foram definidas em função do tipo e quantidade de raízes encontradas em cada estaca. Tratamentos onde a muda formada possuía raízes finas e grossas recebiam pontuações superiores àquelas onde só havia raízes grossas. 


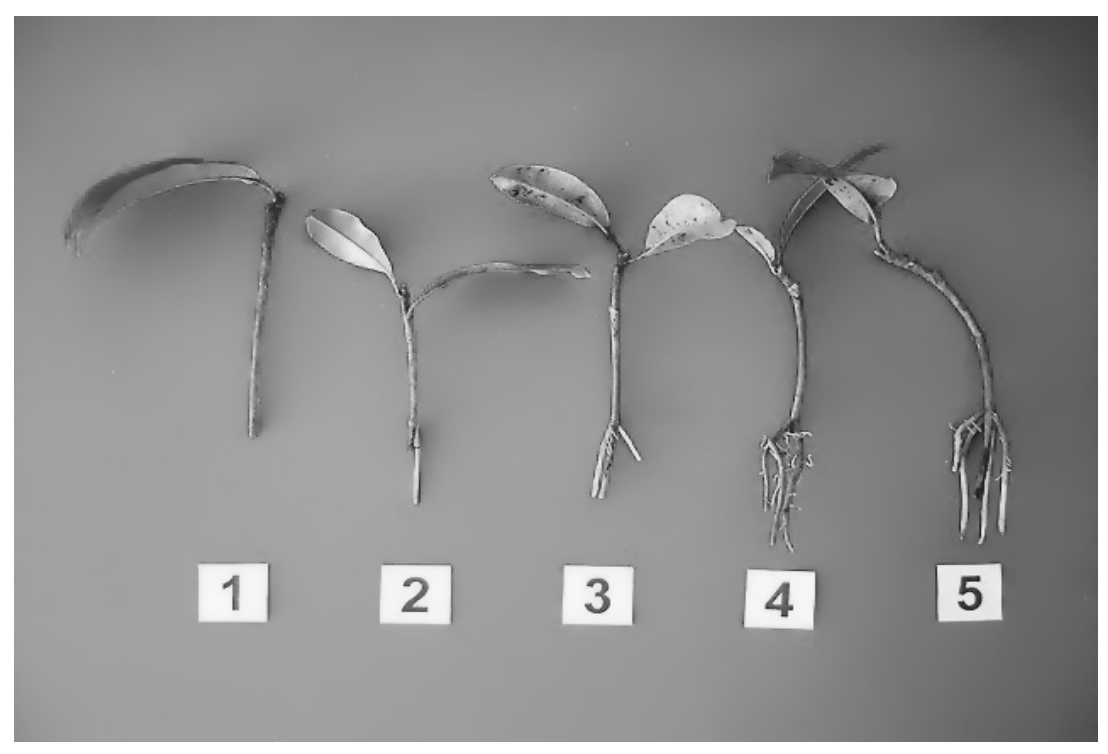

Figura 1. Escala com as notas dadas para as estacas de sapotizeiro utilizadas: (1) nota $1=$ estaca viva, mas com ausência de raízes; (2) nota 2 = estacas com enraizamento ruim; (3) nota 3 = estacas com enraizamento regular; (4) nota 4 = estacas com enraizamento bom; (5) nota 5 = estacas com enraizamento ótimo.

As observações foram realizadas, semanalmente, por um período de 6 meses, prazo esse definido pela observação das raízes adventícias que começavam a aparecer para fora do substrato na parte inferior da bandeja. Foram coletadas informações sobre o número de estacas que permaneceram vivas, o número de estacas enraizadas, e neste caso, notas referentes à qualidade de cada raiz formada. Estas avaliações foram analisadas por meio do programa estatístico SAS (2003).

\section{RESULTADOS E DISCUSSÃO}

Verificou-se pelos dados da Tabela 1, que no enraizamento das estacas do sapotizeiro, o Plantmax® e a fibra de coco possibilitaram o maior número de estacas enraizadas $(39$ e 32 respectivamente), além do maior número de estacas vivas (72 e 75 respectivamente), fato este também observado por Pio et al. (2005), com enraizamento de estacas de figueira.

No caso do substrato areia, os valores mostram que ela não foi diferente da fibra de coco e do Plantmax ${ }^{\circledR}$, no que se refere ao número de estacas vivas (EV), mas, diferiu do Plantmax ${ }^{\circledR}$ em relação ao número de estacas enraizadas, o que não aconteceu em relação à fibra de coco para este mesmo parâmetro de observação. 
Tabela 1. Número de estacas total (ET), vivas (EV), enraizadas (EE) e a média aritimética das notas de cada estaca enraizada (Notas/EE).

\begin{tabular}{ccccc}
\hline Substrato & ET & EV & EE & Notas/EE \\
\hline Areia & 90 & $67 \mathrm{a}$ & $25 \mathrm{bc}$ & 3,12 \\
Plantmax ${ }^{\circledR}$ & 90 & $72 \mathrm{a}$ & $39 \mathrm{a}$ & 2,41 \\
Fibra de Coco & 90 & $75 \mathrm{a}$ & $32 \mathrm{ab}$ & 2,91 \\
Casca de Café & 90 & $54 \mathrm{~b}$ & $19 \mathrm{c}$ & 2,68
\end{tabular}

Médias seguidas da mesma letra minúscula na coluna não diferem entre si, pelo teste de Tukey a 5\% de probabilidade.

Luz et al. (2007), avaliando o enraizamento de hortênsia, verificaram que o substrato areia foi onde as plantas apresentaram os melhores resultados quanto à qualidade das raízes e também à porcentagem de enraizamento. Costa et al. (2007) observaram que este mesmo substrato, com estacas de Ocimum selloi (Benth), também foi recomendado como substrato para enraizamento do material vegetal avaliado. O mesmo não foi verificado para o sapotizeiro cuja tabela 1 mostra que o substrato areia proporcionou enraizamento em apenas 25 das 90 estacas avaliadas $(27,7 \%)$. Resultado semelhante ocorreu no experimento realizado por Bona et al. (2005), com estacas de diversas partes do ramo de carqueja, onde o substrato areia foi o que proporcionou a menor porcentagem de enraizamento.

Autores como Tofanelli et al. (2002) e Mindêllo Neto (2006), trabalhando com fruteiras, basearam-se em dados como o número médio de raízes por estaca e comprimento da maior raiz, que são aspectos quantitativos comuns em trabalhos de estaquia.

Neste experimento, o enraizamento do sapotizeiro mostrou a formação de dois tipos distintos de raízes, uma mais grossa e comprida, comum em todas as estacas enraizadas e outra mais fina e curta obtida em algumas estacas (Figura 1). Em virtude desta peculiaridade, optou-se pela avaliação qualitativa, através da escala de notas, como os relatados por Cornélio et al. (2000) e Maringoni e Souza (2003).

A avaliação por notas, neste caso, definiu melhor a qualidade das plantas obtidas, visto que avaliações comparativas quantitativas, como a massa seca indicaria como melhores os tratamentos onde haveria mais raízes mais pesadas. No entanto, as raízes finas, que são desejáveis em mudas de alta qualidade, após o período de secagem em estufa, apresentam valores de massa seca inferior à dos tratamentos onde houve predominância de raízes mais grossas que são mais pesadas e erroneamente indicariam que as plantas com maior valor de massa seca de raízes seriam as de melhor qualidade.

Segundo Raven et al. (2007), quanto maior a quantidade de raízes mais finas, maior é 
a superfície de absorção da raiz, que define um ótimo sistema radicular. As raízes jovens em crescimento são as envolvidas na absorção de águas e íons orgânicos e é extremamente importante para um sistema radicular bem formado (RAVEN et al., 2007), possibilitando altos índices de pegamento no transplantio desta para o local definitivo.

As notas conferidas em cada tratamento deste trabalho foram somadas e calculadas em função no número de estacas enraizadas para cada tratamento, e que apesar de ter enraizado apenas 25 das 90 estacas enraizadas, a nota média das raízes obtidas no substrato areia $(3,12)$, foram maiores que as da fibra de coco $(2,91)$, casca de café $(2,68)$ e Plantmax ${ }^{\circledR}(2,41)$.

É possível observar-se na Tabela 1 , que em relação à qualidade da raiz formada na estaca em cada tratamento, que o substrato Plantmax ${ }^{\circledR}$ foi o que mais possibilitou o enraizamento das raízes, mas de qualidade inferior aos demais. Pois, até o tratamento casca de café carbonizada, que permitiu o menor número de estacas vivas e o menor número de estacas enraizadas obteve estacas com raízes com qualidade maior $(2,68)$ que as obtidas no substrato Plantmax® $(2,41)$.

Apesar de não existir diferença significativa entre o substrato Plantmax®, e a fibra de coco no que se refere ao número de estacas vivas e número de estacas enraizadas, a avaliação por meio da escala de notas demonstrou que a fibra de coco, promoveu raízes de melhor qualidade que o Plantmax®.

O substrato areia apresentou a nota média de maior valor para a variável 'número de estacas enraizadas' $(3,12)$, no entanto, a freqüência de enraizamento obtida neste material, foi baixa, com raízes formadas em apenas $27,7 \%$ do total de estacas.

\section{CONCLUSÃO}

1- Os substratos Plantmax® e Fibra de Coco permitem o maior número de estacas enraizadas;

2- O substrato areia permite a formação de raízes de melhor qualidade, pela escala de notas.

\section{REFERÊNCIAS}

AZEREDO, G.A. Desempenho de sementes de sapoti (Achras sapota L.) submetidas a diferentes tratamentos pré-germinativos. Revista Brasileira de Fruticultura, Jaboticabal, v. 24, n. 1, p. 147-150, abr. 2002. 
BONA, C. M. de et al. Estaquia de três espécies de Baccharis. Ciência Rural, Santa Maria, v. 35, n. 1, p. 223-226, jan./fev. 2005.

BANDEIRA, C. T. et al. O cultivo do sapotizeiro. 2. ed. Fortaleza: Embrapa Agroindústria Tropical, 2003. 20 p. (Circular técnica, 13).

CORNÉLIO, V. M. O. et al. Associação entre a incidência de brusone e a presença de Pyricularia grisea nas sementes de arroz. Pesquisa Agropecuária Brasileira, Brasília, v. 35, n. 3, p. 639-645, mar. 2000.

COSTA, L.C. do B.; PINTO, J.E.B.P.; BERTOLUCCI, S.K.V. Comprimento da estaca e tipo de substrato na propagação vegetativa de atroveran. Ciência Rural, Santa Maria, v. 37, n. 4, p. 1157-1160, jul./ago. 2007.

JANGAM, S.V. et al. Studies on dehydration of sapota (Achras zapota). Drying Technology, Philadelphia, v. 26, n. 1-3, p. 369-377, mar. 2008.

LETERME, P. et al., Mineral content of tropical fruits and unconventional foods of the Andes and the rain forest of Colombia. Food Chemistry, v. 95, n. 4, p. 644-652, abr. 2006.

LORENZI, H. et al. Frutas brasileiras e exóticas cultivadas. São Paulo: Instituto Plantarum de Estudos da Flora, 2006.

LEDERMAN, I.E. et al. Sapotizeiro (Manilkara zapota L. von Royen). Jaboticabal: SBF, 2001. 71p. (Série - Frutas Potenciais).

LUZ, P.B. da; PAIVA, P.D. de O.; LANDGRAF, P.R.C. Influência de diferentes tipos de estacas e substratos na propagação assexuada de hortênsia [Hydrangea macrophylla (Thunb.) Ser.]. Ciência e Agrotecnologia, Lavras, v. 31, n. 3, p. 699-703, mai./jun.2007.

MARINGONI, A. C.; SOUZA, E. L. C. Reação de cultivares de soja a isolado de Curtobacterium flaccumfaciens cv flaccumfaciens provenientes de feijoeiro. Pesquisa Agropecuária Brasileira, Brasília, v. 38, n. 6, p. 777-781, 2003.

MINDÊLLO NETO, U. R. Enraizamento de estacas lenhosas de cultivares de ameixeira com aplicação de ácido indolbutírico e cianamida hidrogenada. Pesquisa Agropecuária

Brasileira, Brasília, v. 41, n. 3, p. 529-531, mar. 2006.

MIRANDA, M. R. A. de et al. Armazenamento de dois tipos de sapoti sob condição de ambiente. Revista Brasileira de Fruticultura, Jaboticabal, v. 24, n. 3, p. 644-646, dez. 2002.

MORAIS, P.L.D. et al. Alterações físicas, fisiológicas e químicas durante o armazenamento de duas cultivares de sapoti. Pesquisa Agropecuária Brasileira, Brasília, v. 41, n. 4, p. 549554, abr. 2006.

PIO, R. et al. Substratos no enraizamento de estacas de figueira oriundas da desbrota. Ciência e Agrotecnologia, Lavras, v. 29, n. 3, p. 604-609, mai./jun. 2005.

RAVEN, P. H., EVERT, R. F., EICHHORN, S. E. Biologia vegetal. 7.ed. Rio de Janeiro: Guanabara Koogan, 2007. 858p. 
RIMM, E.B. Fruits and vegetables building a solid foundation. American Journal of Clinical Nutrition, v. 76, n. 1, p. 1-2, jul. 2002.

RUFFATO, L.; KERSTEN, E. Enraizamento de estacas de pessegueiro (Prunus persica (L.) Batsch), cv Esmeralda e BR2, submetidas à estratificação e ao ácido indolbutírico. Revista Brasileira de Fruticultura, Jaboticabal, v. 22, n. 2, p. 191-194, ago. 2000.

SAS. SAS OnlineDoc, Version 9.1.3 Cary, NC, USA: SAS Institute Inc, 2003.

TOFANELLI, M.B.D. et al. Efeito do ácido indolbutírico no enraizamento de estacas de ramos semilenhosos de pessegueiro. Pesquisa Agropecuária Brasileira, Brasília, v. 37, n. 7, p. 939-944, jul. 2002. 